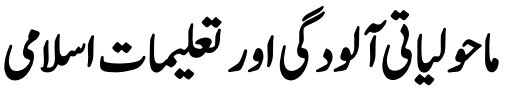

\section{Environmental pollution and teachings of Islam}

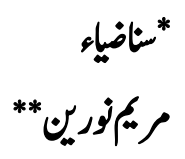

\begin{abstract}
Man is Allah's vicegerent on earth. The fulfillment of this sacred role requires immense power, and for this purpose, Allah has made Nature subservient to human beings. All natural objects and phenomena not only beautify the universe, but also are the source for its nourishment. That is why the survival of earth depends on the integrity of environment.Environment plays an integral role in human life. Providence has created balance in environment which is being destroyed by harmful human activities. Pollution has become a worldwide problem. Different toxic matters and deforestation has made our earth a dangerous abode for us. As Islam has guidelines for every aspect of life, so in the same way, it asks human beings to preserve the environment. Our prophet's traditions are full of golden principles to preserve our surroundings. He advised his followers to cover the edibles to protect them from toxic elements in the environment. Moreover, he encouraged us to plant more and more trees, and ensured blessings for the cultivators if their fruits are eaten by other creatures. Hence our environment can be better looked after, if we follow the principles of Islam. This paper discusses our prophet's teachings on the protection and preservation of environment, and the following of these principles can save us and the coming generations from all ailments and impurities.
\end{abstract}

Key Words: Pollution, Islamic teachings,water,Air, Land.

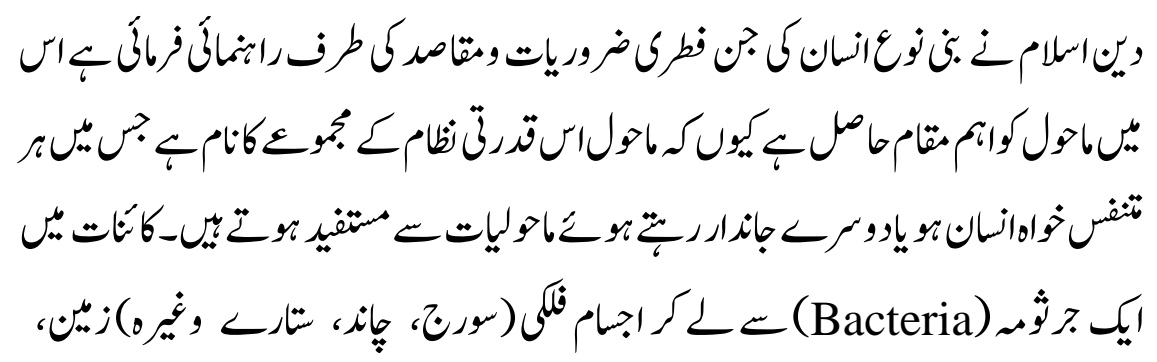

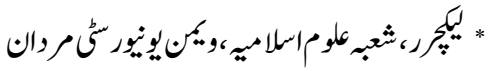

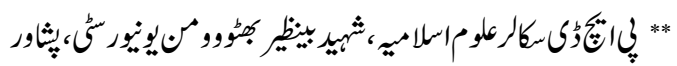




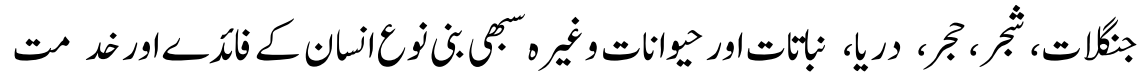

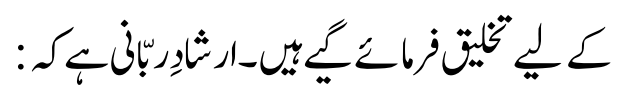

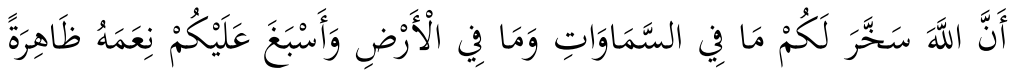
1

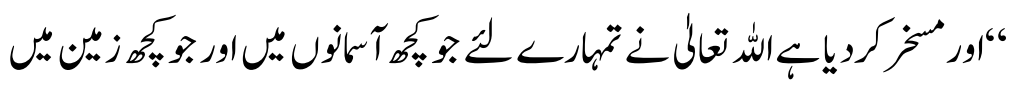

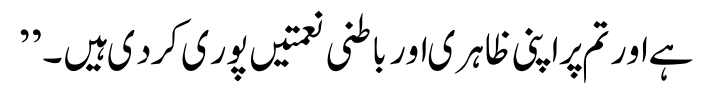

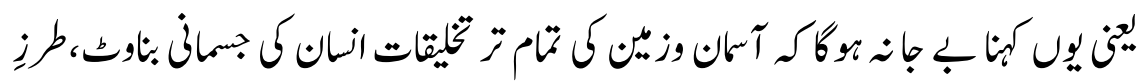

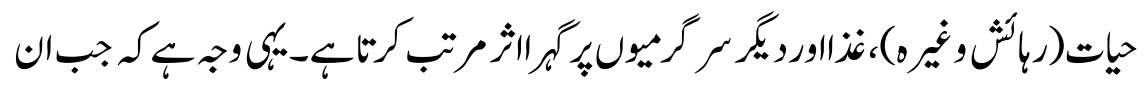

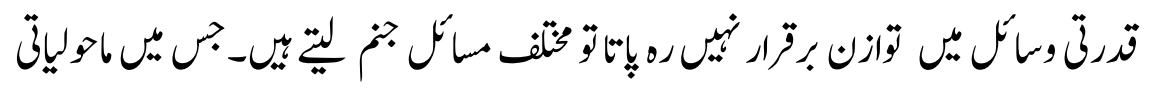

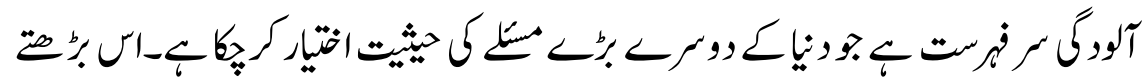

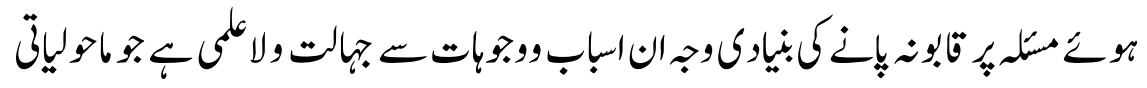

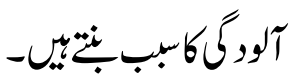

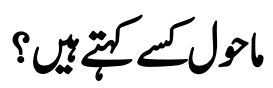

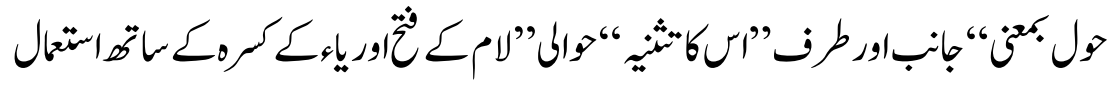

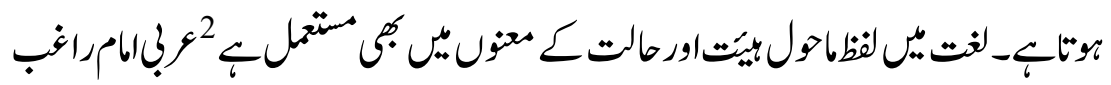

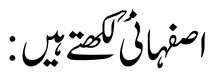

وحَوْلُ الثيء:جانبه الذي يمكنه أن يحوّل إليه3

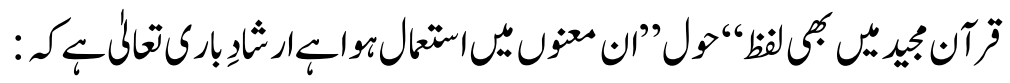

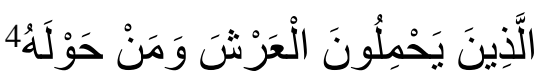

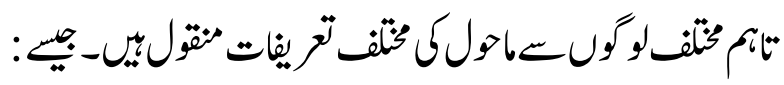

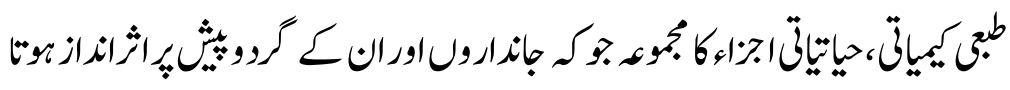

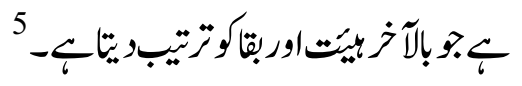




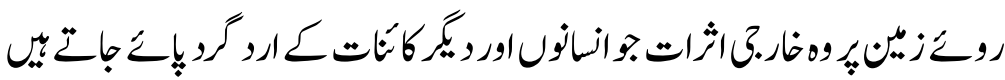

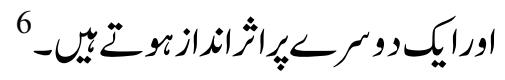

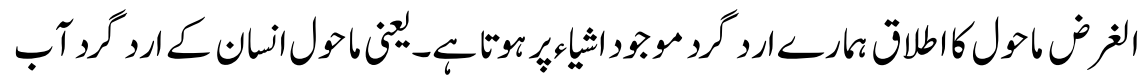

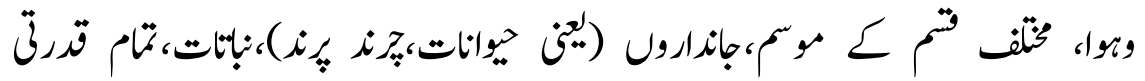

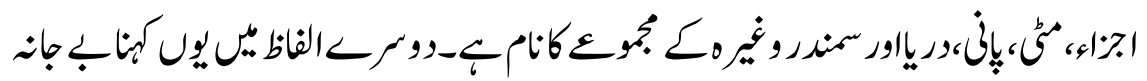

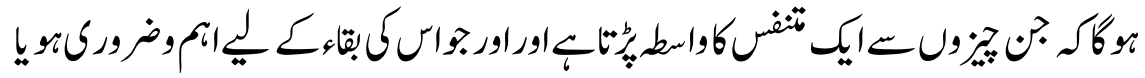

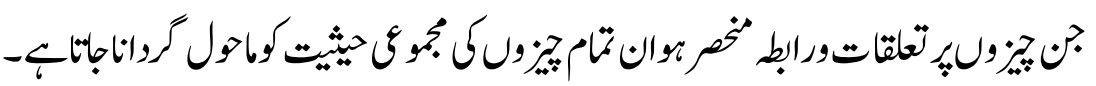

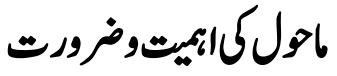

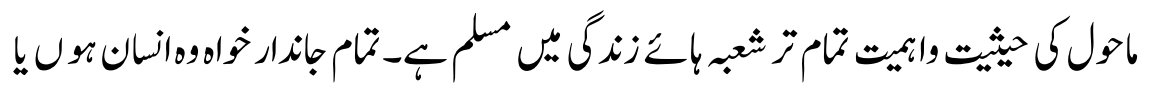

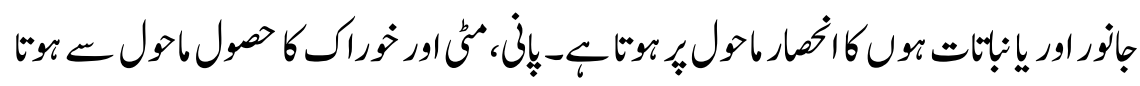

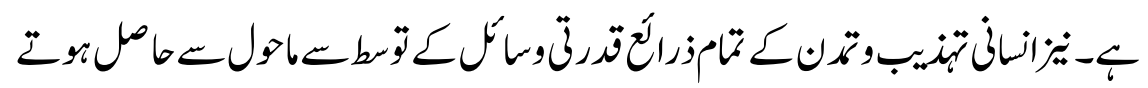

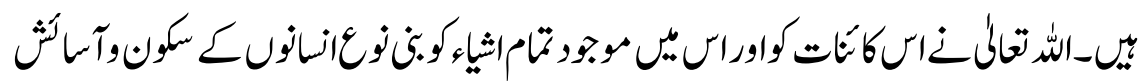

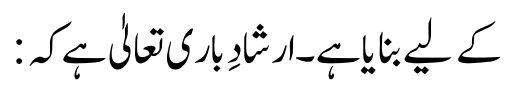

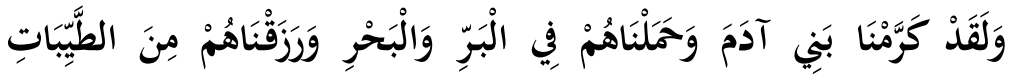

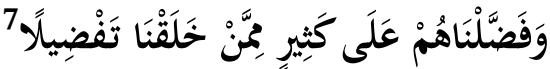

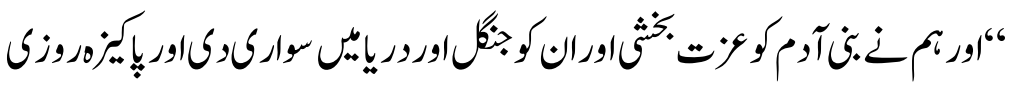

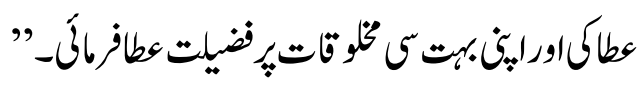

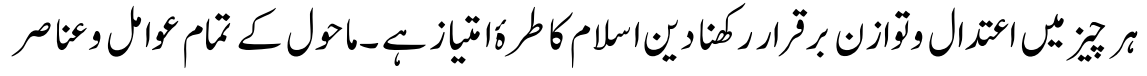

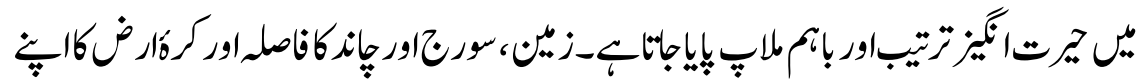

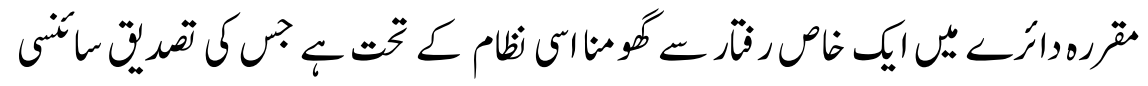

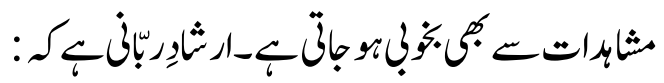
8 


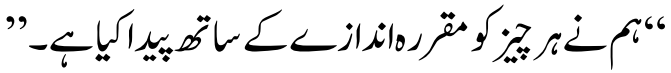

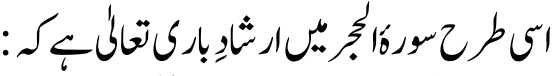

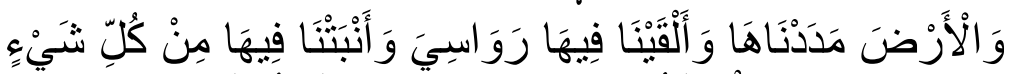

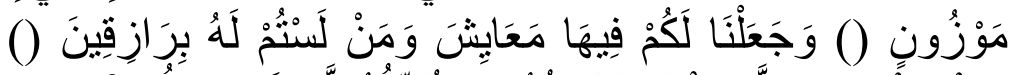

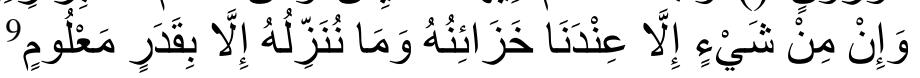

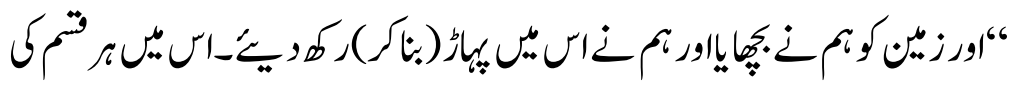

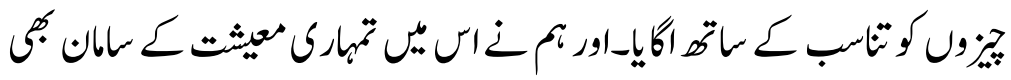

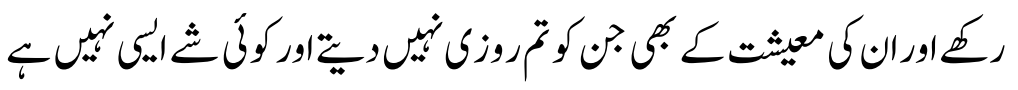

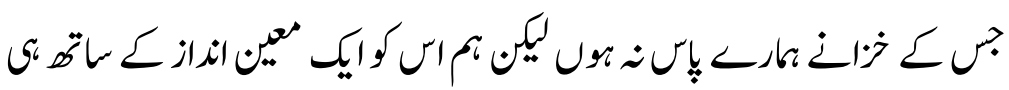
" إن

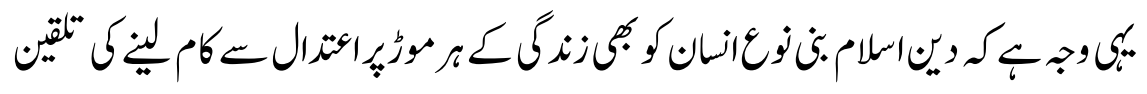

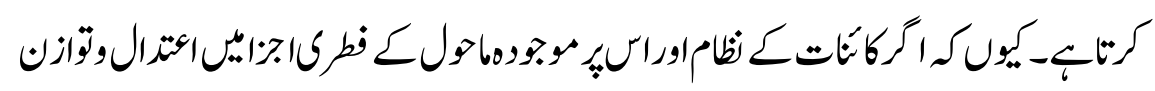

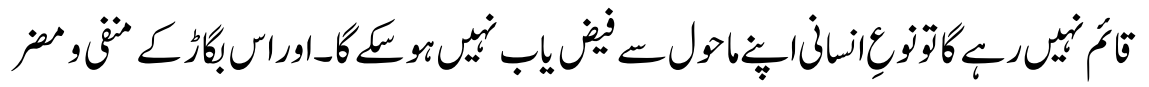

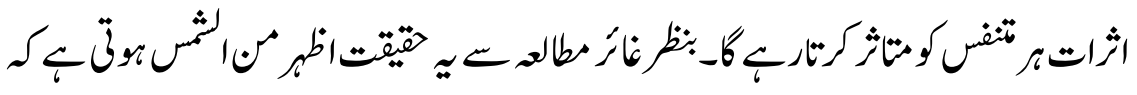

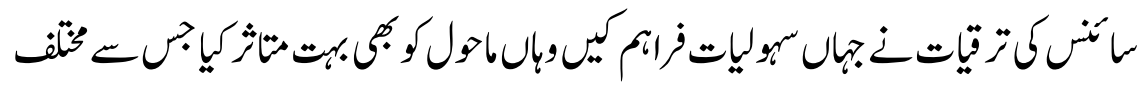

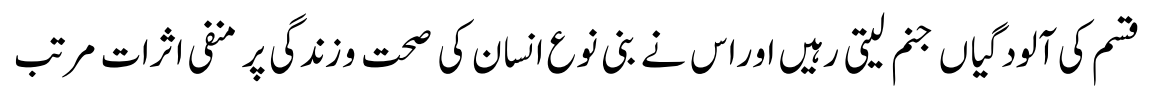

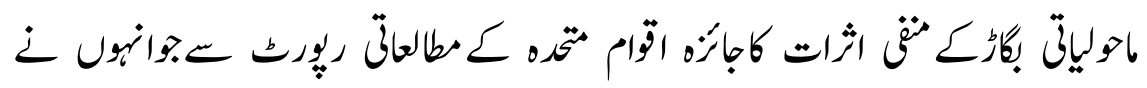

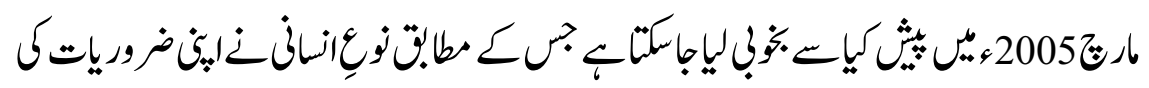

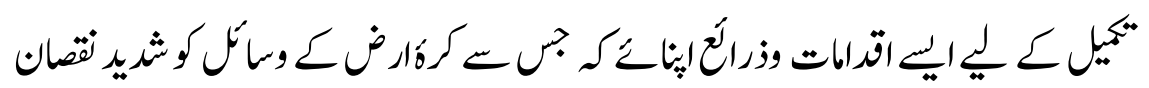

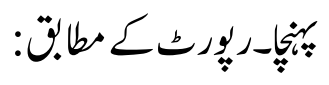

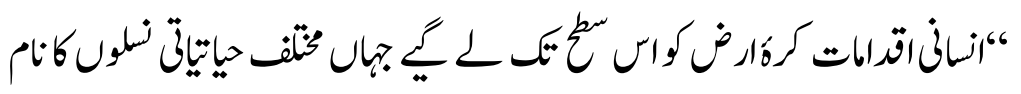

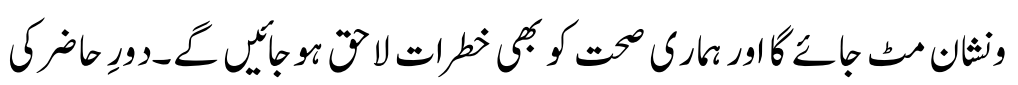




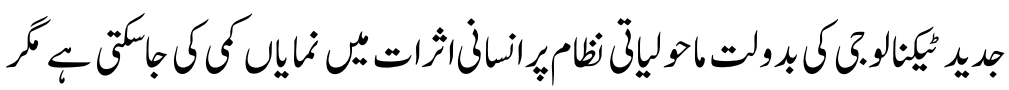

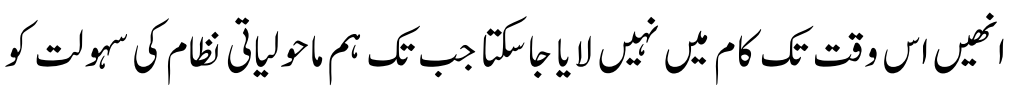

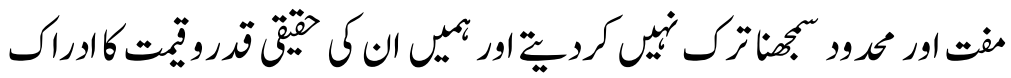

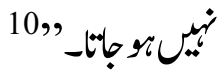

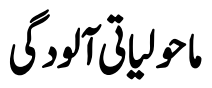

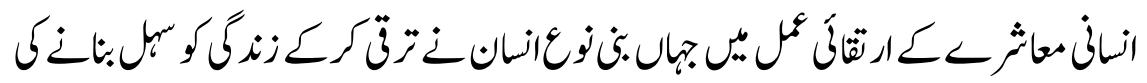

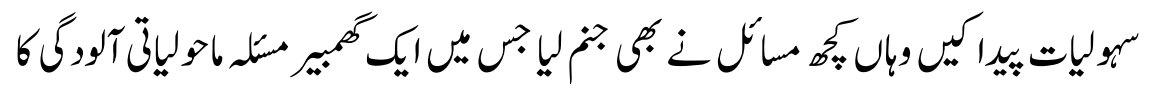

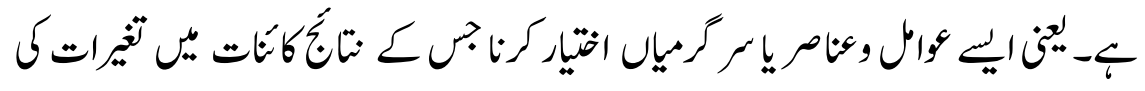

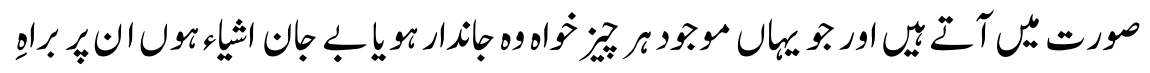

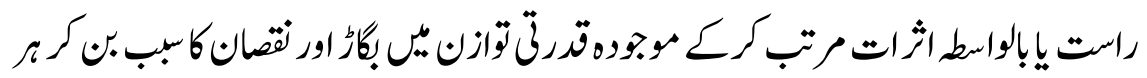

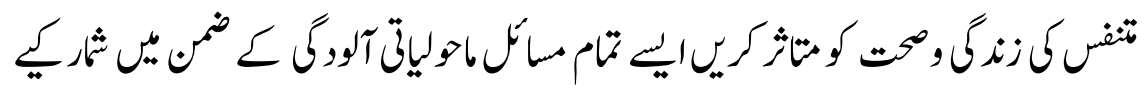

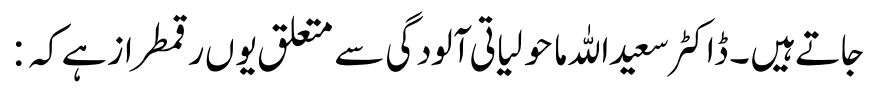

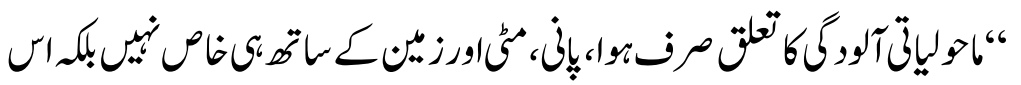

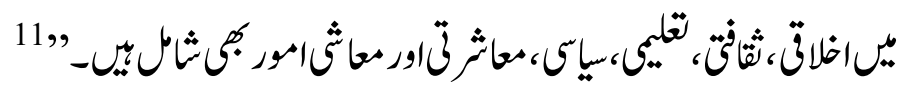

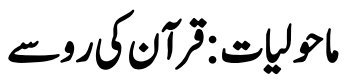

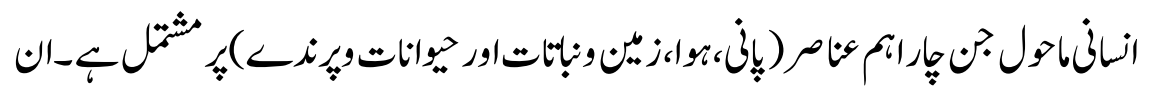

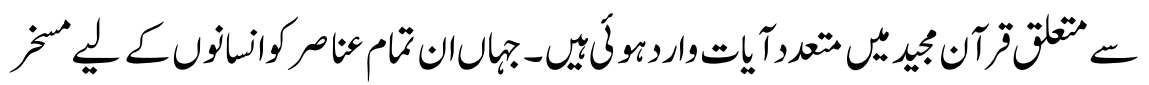

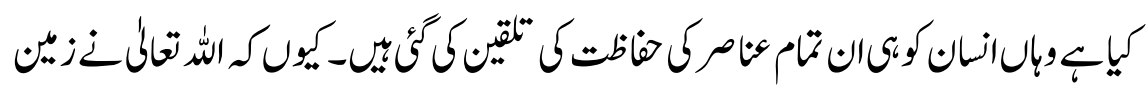

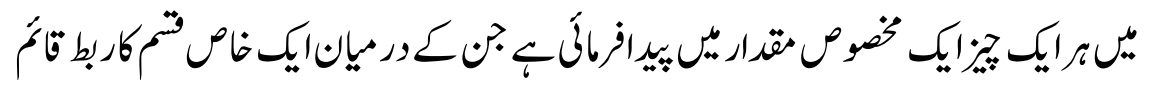

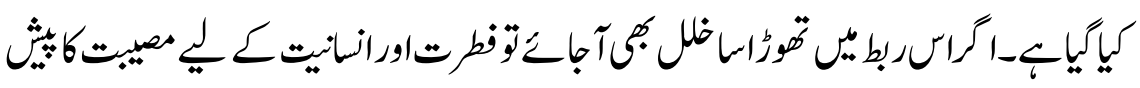

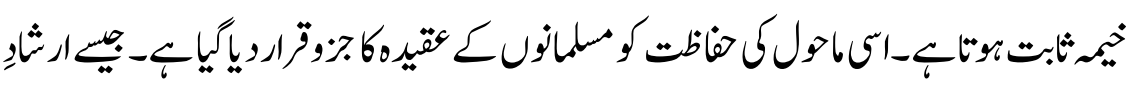
باركتالكَ 


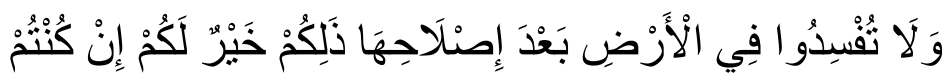
مُؤَمْنِينَ 12

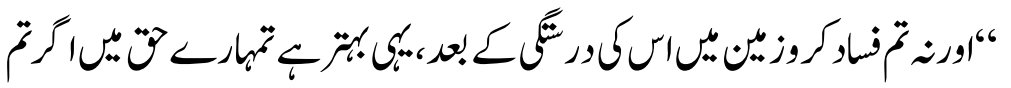

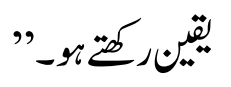

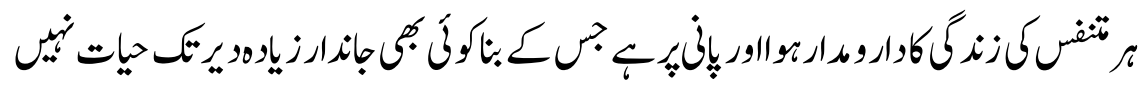

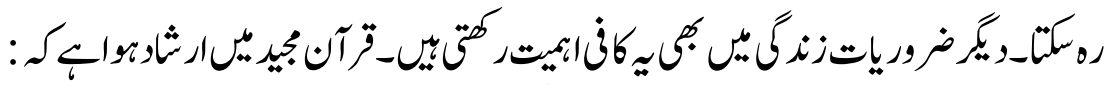

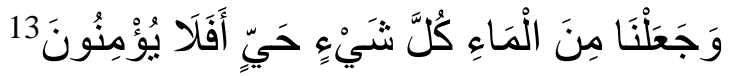

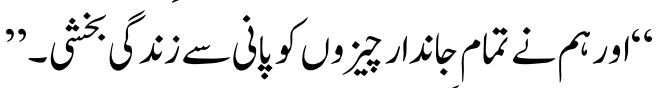

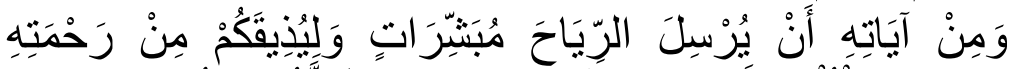

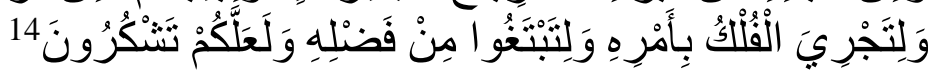

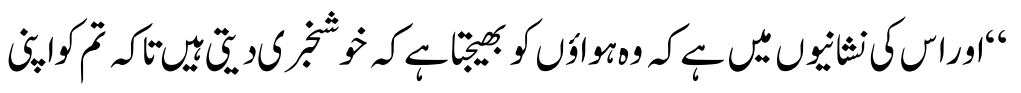

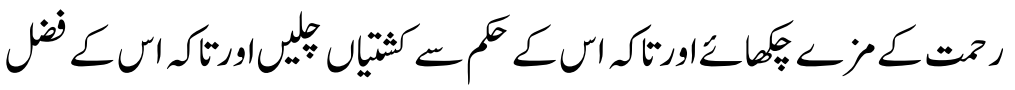

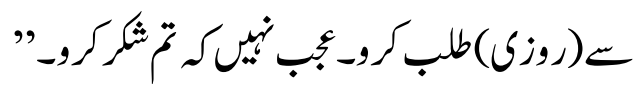

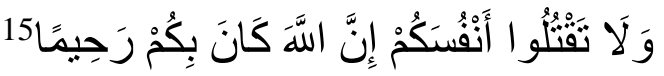

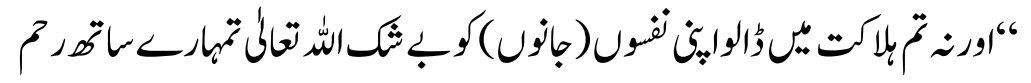

$$
\text { كرنوالاب- }
$$

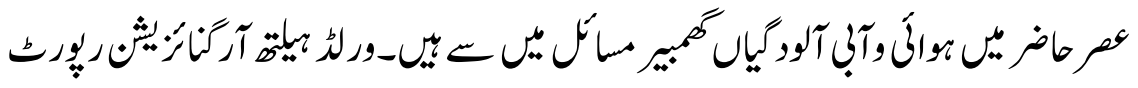

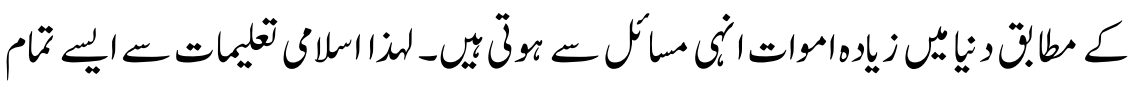

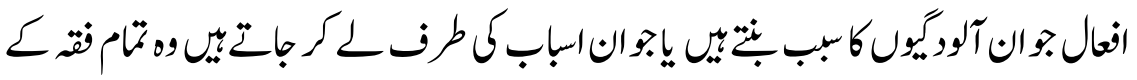

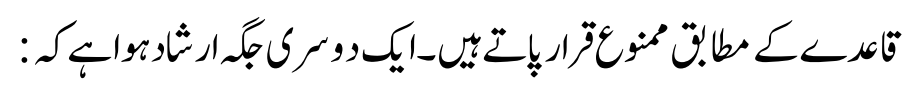

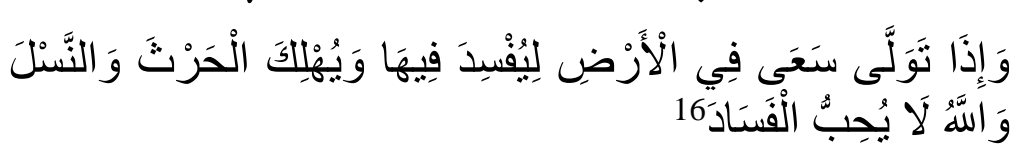

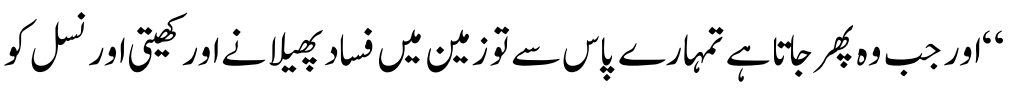

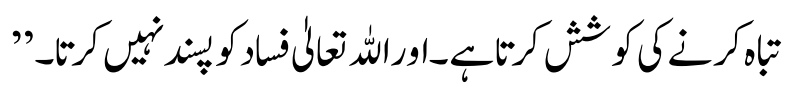




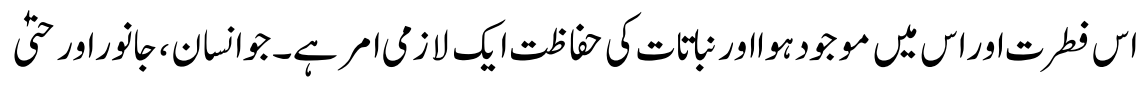

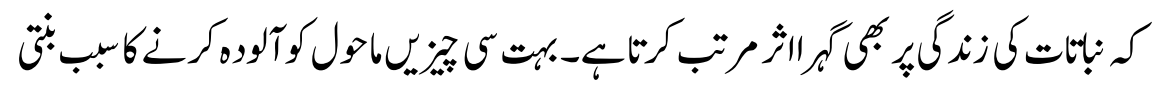

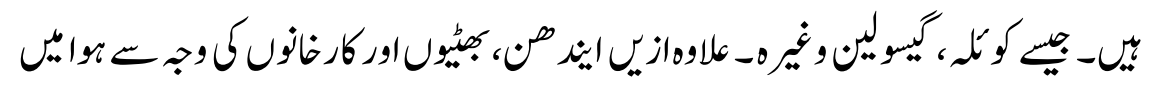

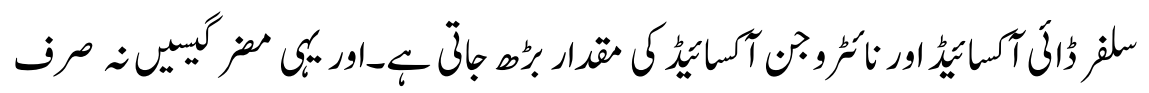

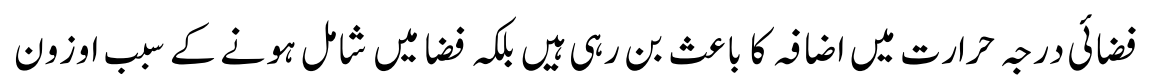

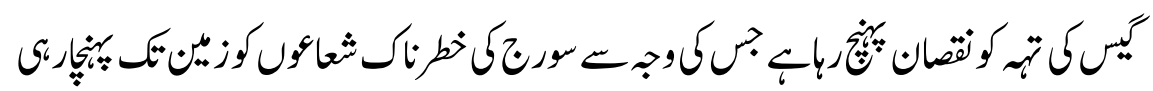

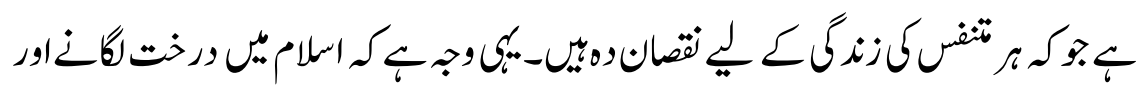

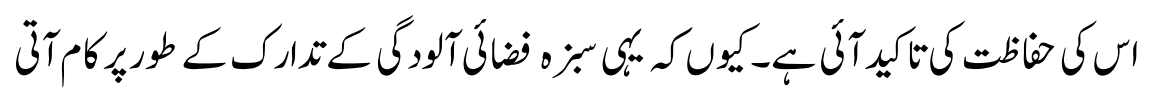

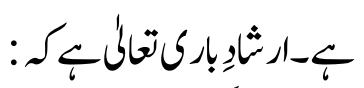

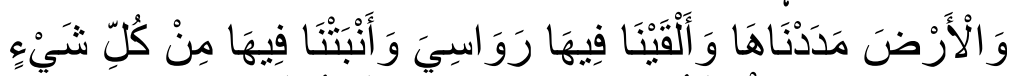

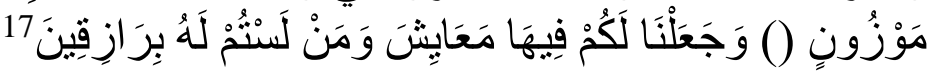

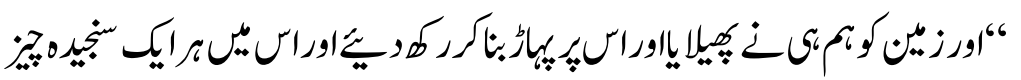

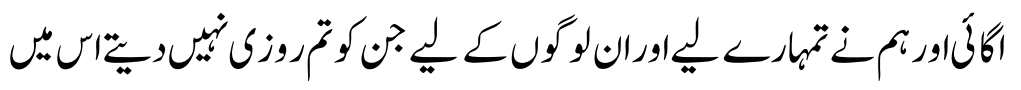

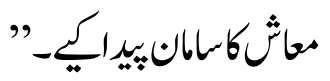

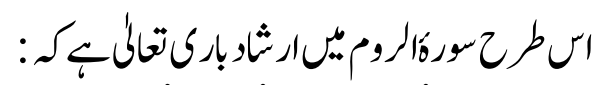

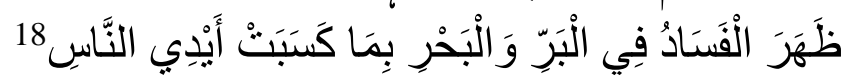

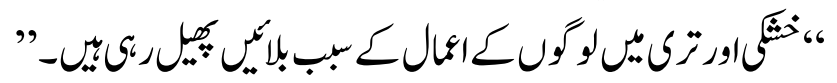

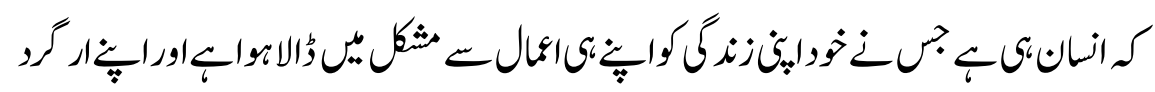

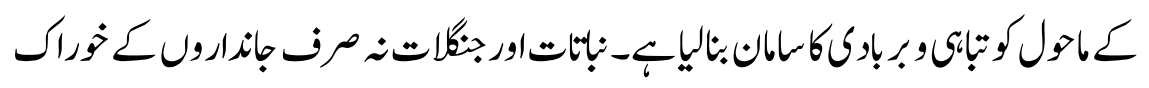

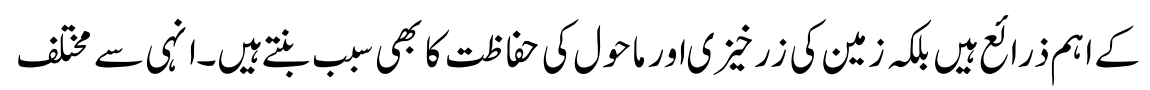

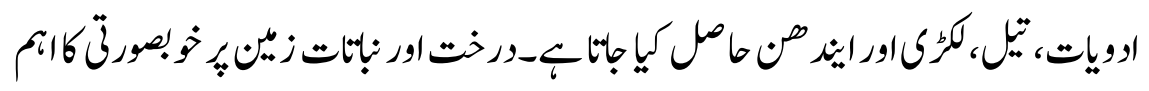

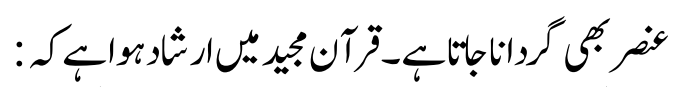

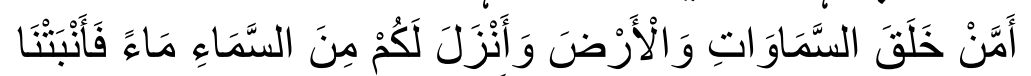

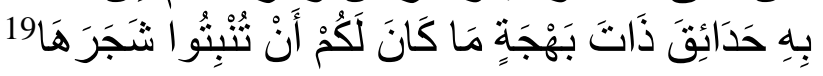




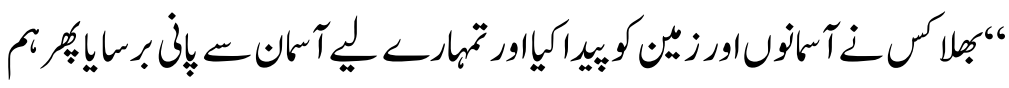

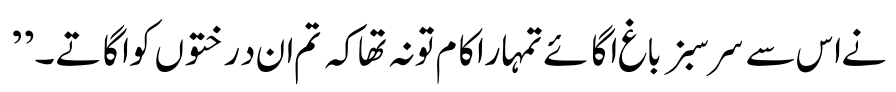

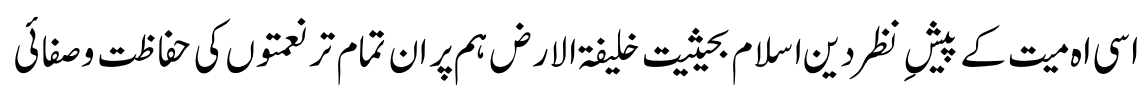

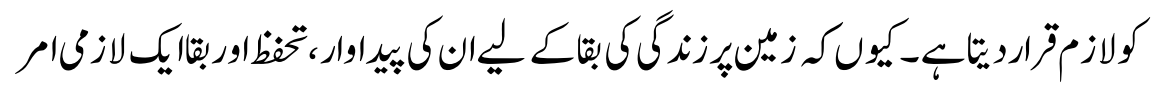

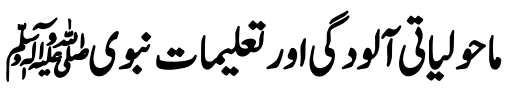

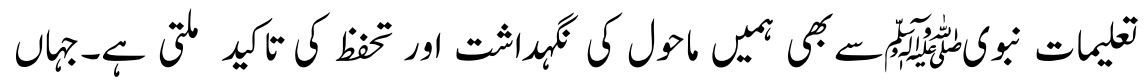

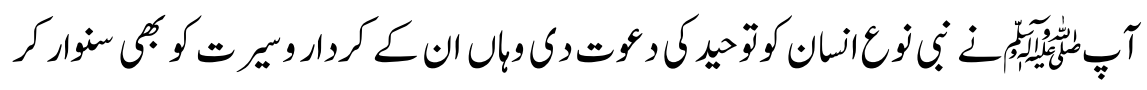

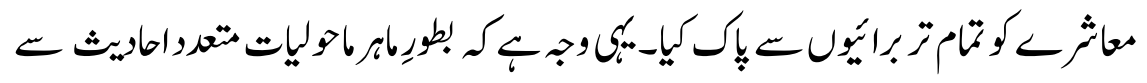

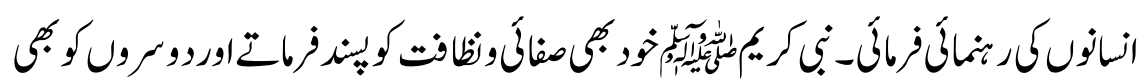

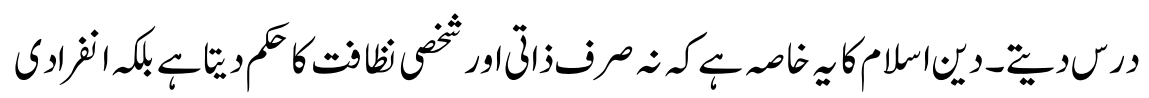

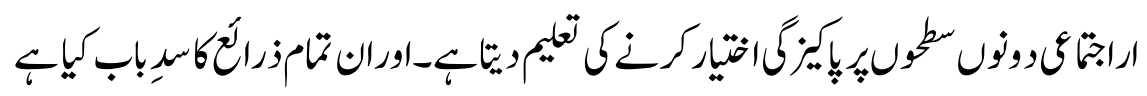

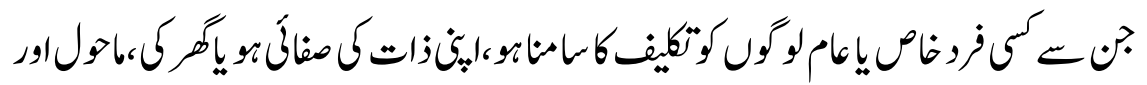

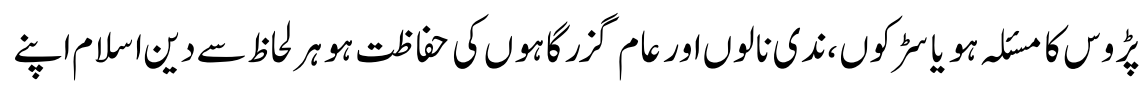

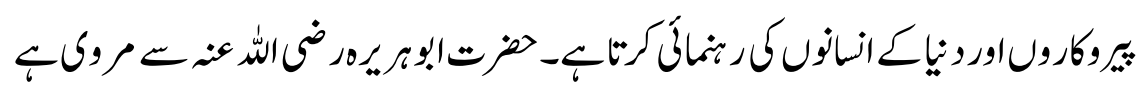

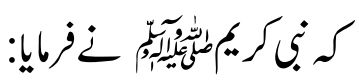

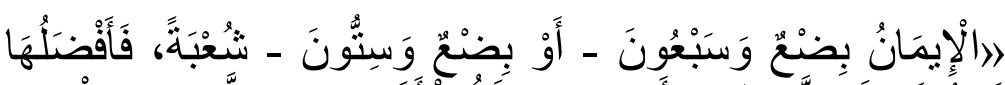

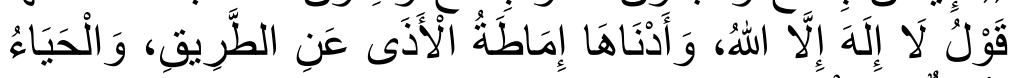

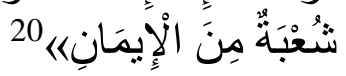

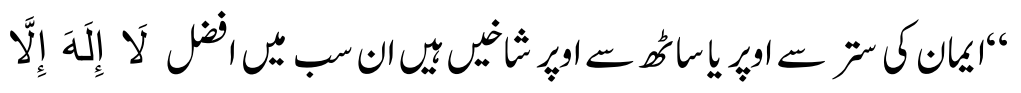

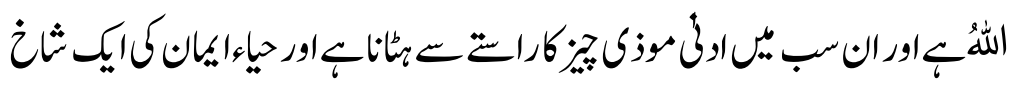

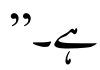




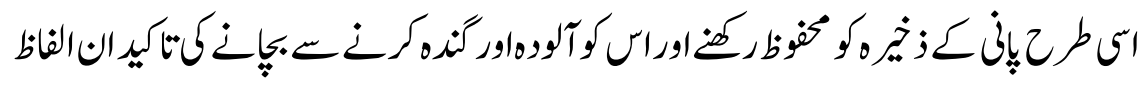

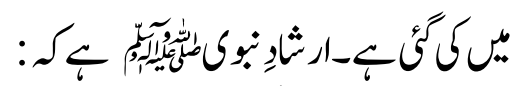

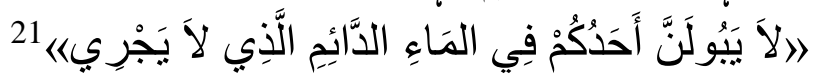

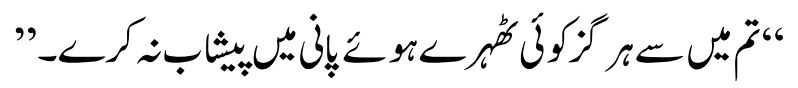

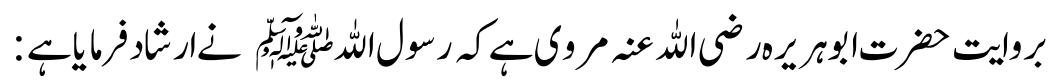

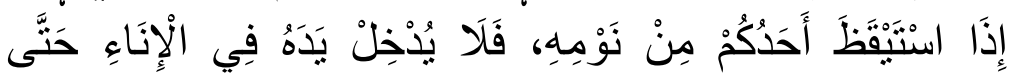

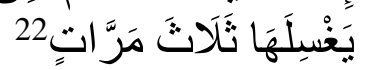

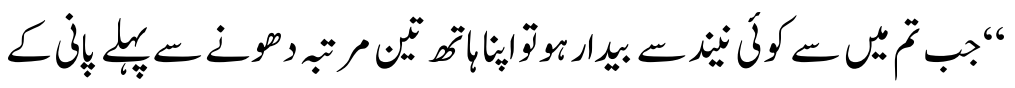

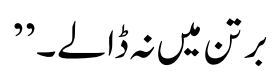

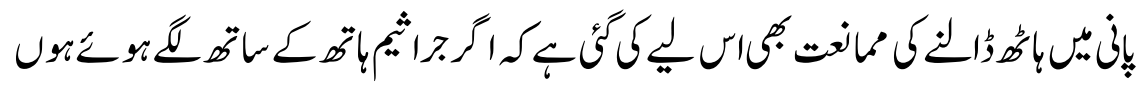

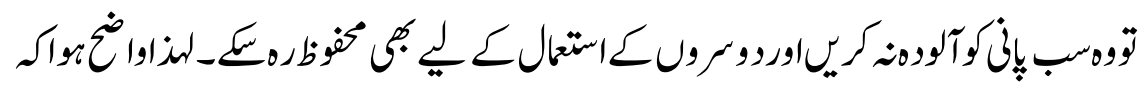

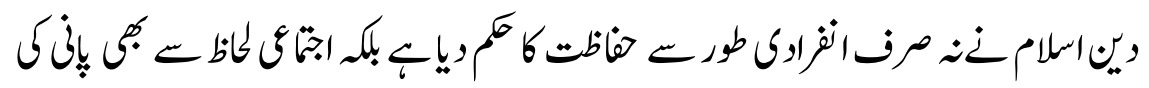

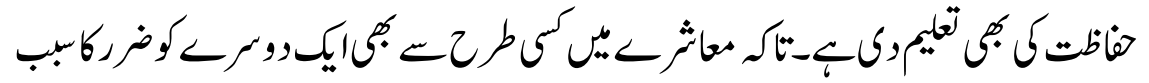

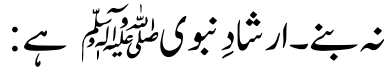

$$
\begin{aligned}
& 23
\end{aligned}
$$

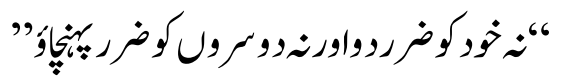

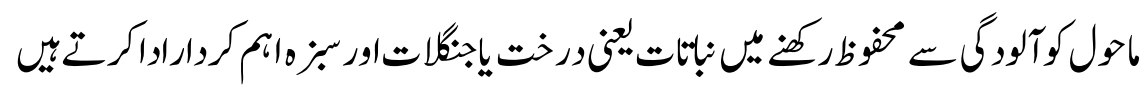

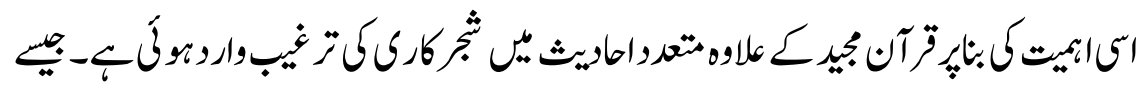

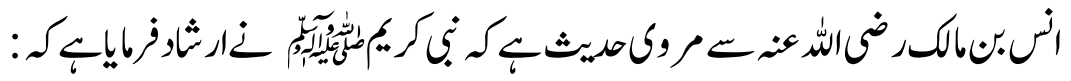

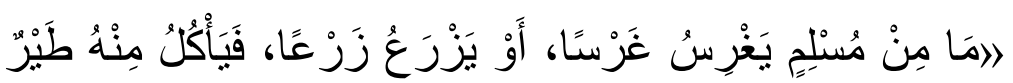

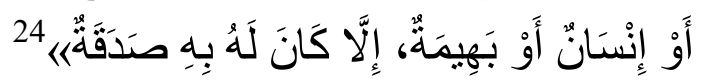




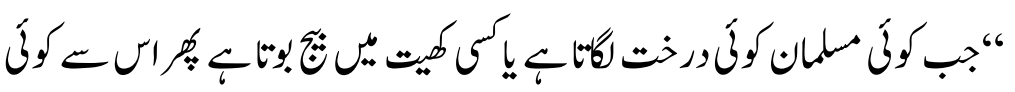

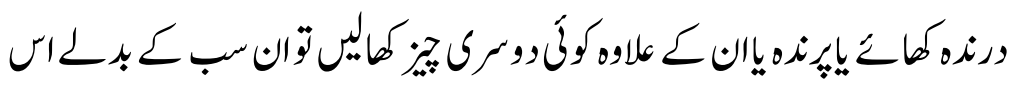

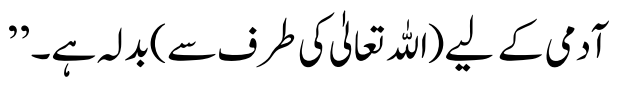

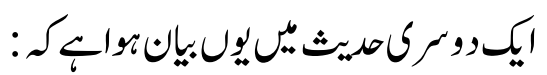

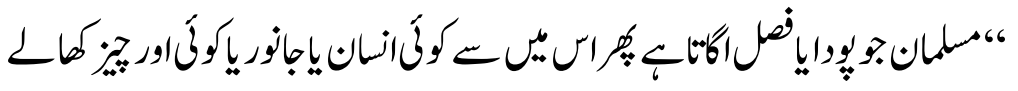

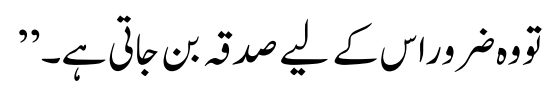

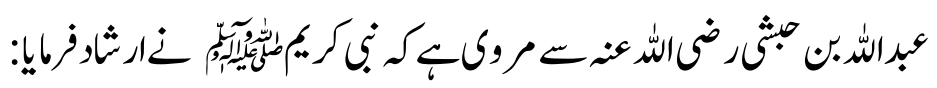

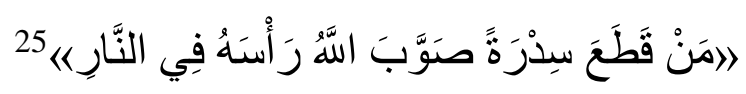

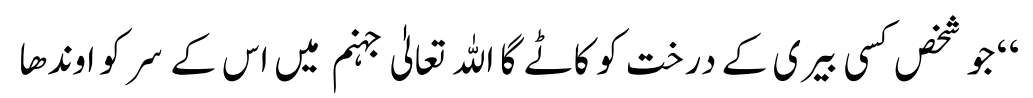

$$
\text { كروبـ }
$$

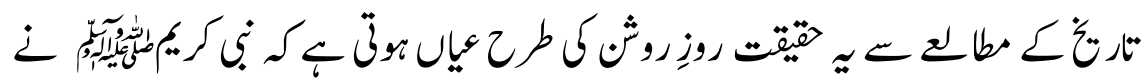

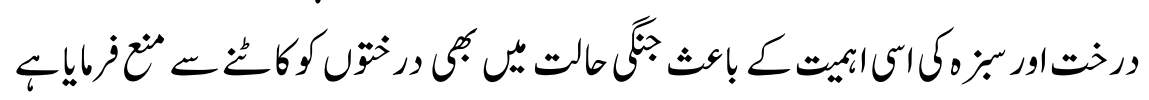

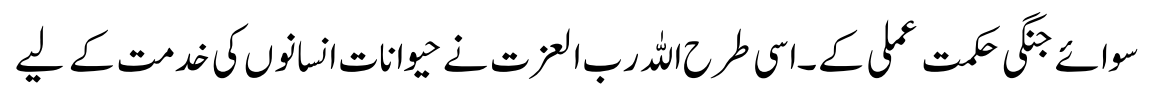

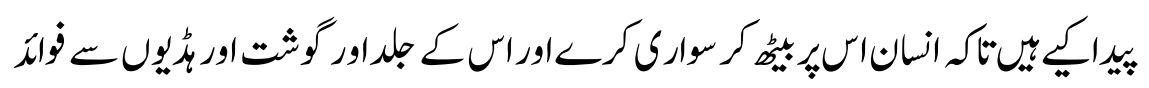

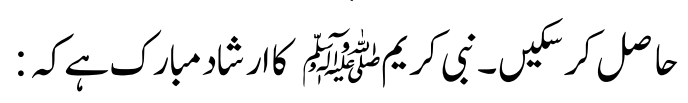

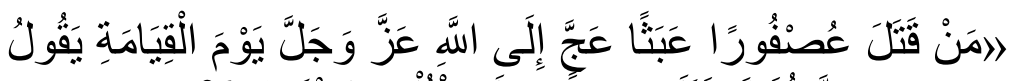

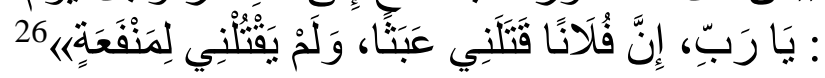

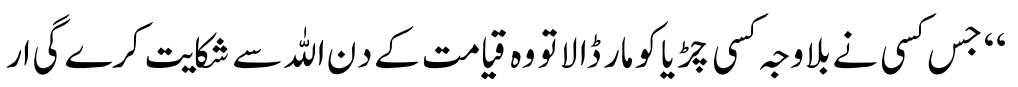

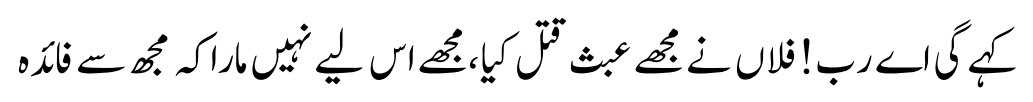
”之占

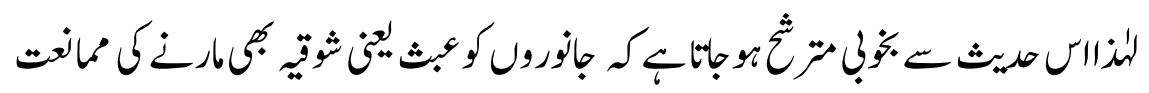

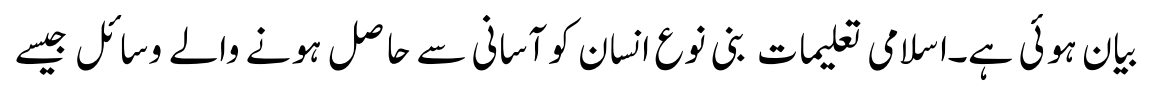




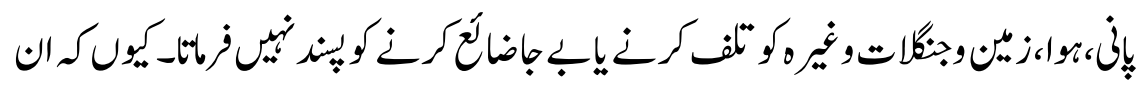

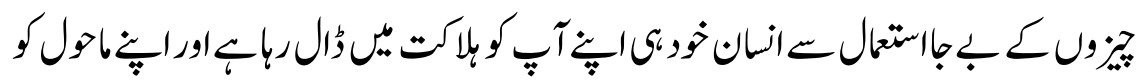

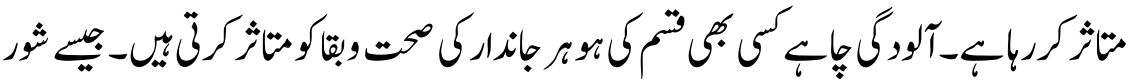

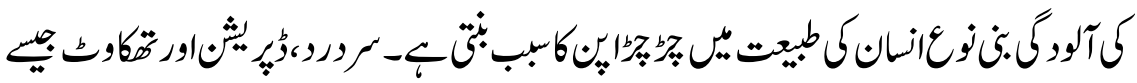

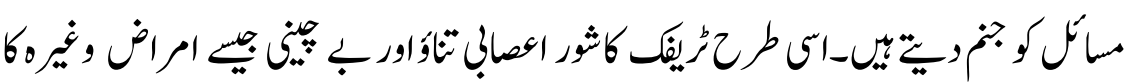

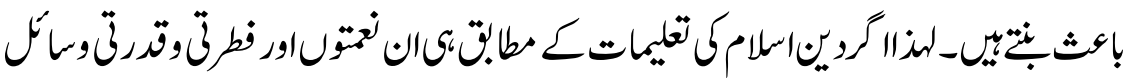

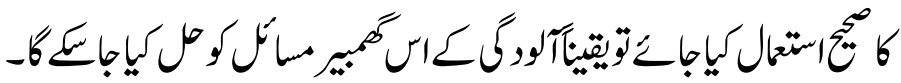

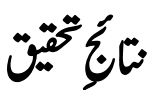

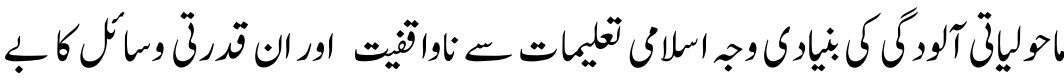

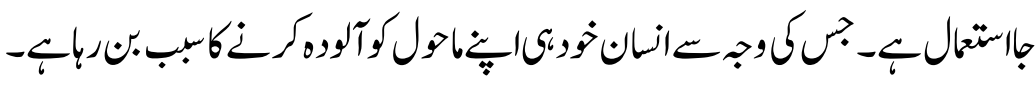

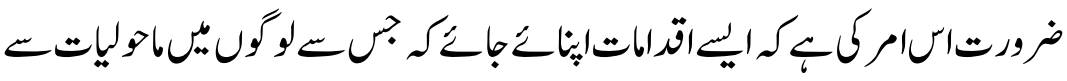

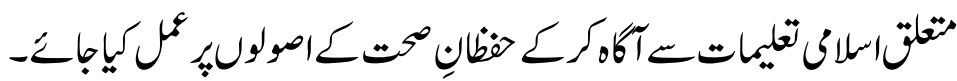

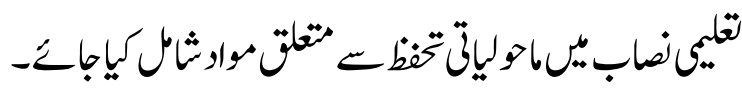

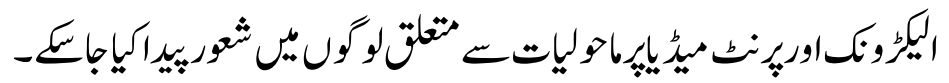

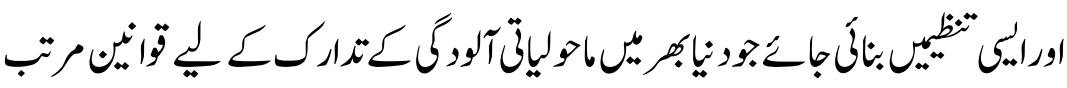

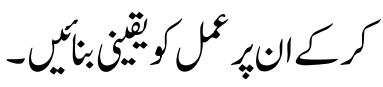

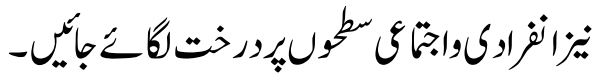

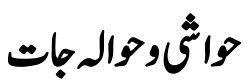




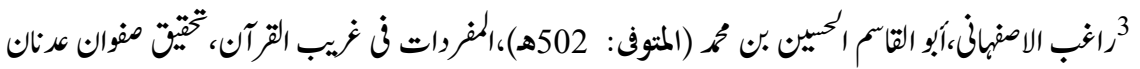

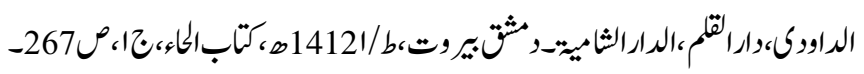

$$
\begin{aligned}
& \text { 4التر آن، بورةثناز }
\end{aligned}
$$

${ }^{5}$ http://www.encyclopediabrittanica/ environment .

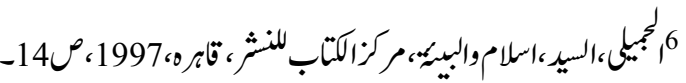

$$
\begin{aligned}
& \text { 7الثز آن، بورةًالاتراء:70 } \\
& \text { 8 }
\end{aligned}
$$

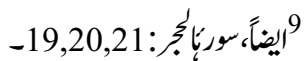

${ }^{10}$ Reid, Walter V, Echo system and Human being, Island Press, Washington, 2005, P\#1, Report of the Millennium Ecosystem Assesstment.

${ }^{11}$ Qazi, Saeedullah, Environment and Islam, Dawah academy,International Islamic,university, Islamabad, $\mathrm{p} \# 1$.

$$
\begin{aligned}
& \text { 12 1اتر آن، بورة|الا واف:85- } \\
& \text { 13 13يضًا، سورة النبياء:30- } \\
& \text { 14 إيضاً، سورةالروم:46 } \\
& \text { 15 15ايضًا، بورة/النساء:29- } \\
& \text { 16 1ايضاً، بورة/ابثرة:205- }
\end{aligned}
$$

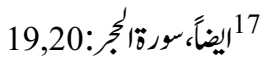

$$
\begin{aligned}
& \text { 18 } \\
& \text { 19 19ايضاً، وبورة|نمل: 60- }
\end{aligned}
$$

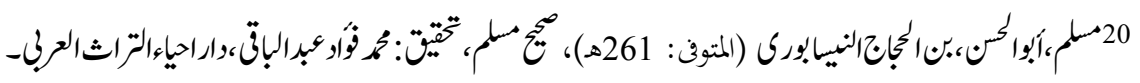

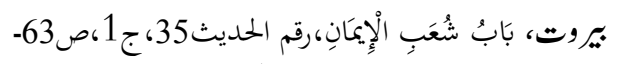

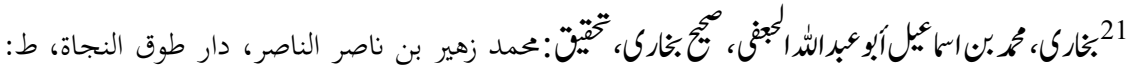

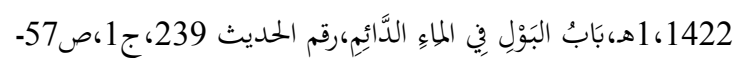

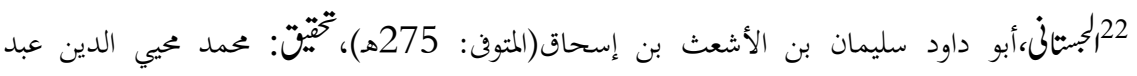

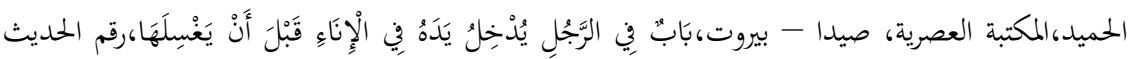


23 ابن ماجة أبو عبد الله محمد بن يزيد القزويني(المتوف: 273هـ)، سنن ابن ماجه،تحقيق: محمد فؤاد عبد

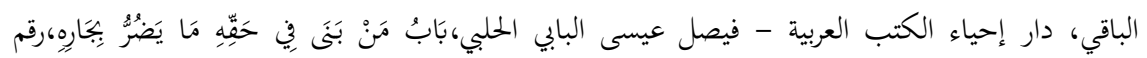
الحديث 2340، ج2، 20184

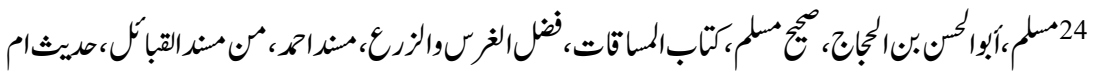

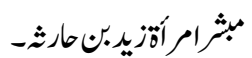

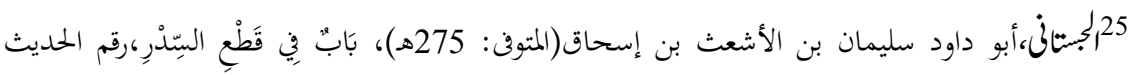
5239 4 4، 361

26 النسائي، أبو عبد الرحمن أحمد بن شعيب بن علي الخراساني(المتوف: 303هـ)، السنن الصغرى للنسائي

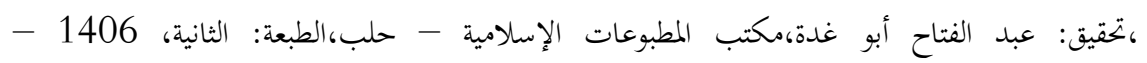

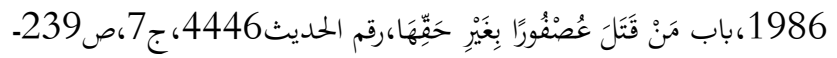

